\title{
Runway Inspection by RPAS
}

\section{The Use of the RPAS for the Inspection of the Airport Operating Areas}

\author{
Ing. Stanislav Absolon \\ Department of Air Transport \\ CTU in Prague, Faculty of Transportation Sciences \\ Prague, Czech Republic \\ absolsta@fd.cvut.cz \\ Ing. David Hůlek \\ Department of Air Transport \\ CTU in Prague, Faculty of Transportation Sciences \\ Prague, Czech Republic \\ hulekdav@fd.cvut.cz
}

\author{
Ing. Hana Trešlová \\ Department of Air Transport \\ CTU in Prague, Faculty of Transportation Sciences \\ Prague, Czech Republic \\ treslhan@fd.cvut.cz \\ Bc. Martina Skálová \\ Department of Air Transport \\ CTU in Prague, Faculty of Transportation Sciences \\ Prague, Czech Republic \\ skalomar@fd.cvut.cz
}

\begin{abstract}
This article discusses the use of the RPAS for the inspection of the airport operating areas. The paper compares the current process of the inspection of the airport operating areas by the airport staff with the possibilities which are offered by the use of the modern technology RPAS. The following text also describes how to inspect airport operating areas by the RPAS, specific technical possibilities and the applicable technical solutions. Furthermore there are variants of piloting the RPAS, comparing usable equipment, equipment for video recording and the possibility of using thermal imaging camera in the article.
\end{abstract}

Keywords - RPAS, inspection of the airport operating areas, Annex 14, RWY, airport processes, Flir Tau 2, GoPro 4, thermal imaging camera

\section{INTRODUCTION}

The use of the RPAS and other unmanned technologies is one of the most important topics in the current science. There have not been written so much scientific papers with the topic "the use of the RPAS in practice" so far, which is one of the benefits of this article. The possibilities of using these vehicles/systems are enormous and these possibilities often increase the accuracy and save time and money during different processes. The RPAS can be successfully used in the processes of the air transport and on international airports also. One example of the specific implementation into airport processes is the use of RPAS for the inspection of the airport operating areas, as discussed in the following text.

\section{PRESENT STATE}

It is obvious from Annex 14 or from regulation L14 that all movement areas of the airport have to be inspected and any dangerous objects have to be removed. All the roughness and disruptions of the surface of the runways and taxiways must be checked and monitored also. [1]

Nowadays situation at the Vaclav Havel Airport is that the inspection of the runway is executed at least 4 times a day. Airport operating areas controller goes over the runway and other movement areas by car and looks for dangerous objects, roughness, pavement distress or surface damages. Due to the air traffic at the airports, it is difficult to perform inspections more frequently.

\section{THE PRINCIPLE OF THE INSPECTION BY RPAS}

The RPAS brings a new dimension into the issue. The basic concept is as follows. The concept was mentioned in the presentation "UAVs and Airports" too. [2] The RPAS equipped with a camera and image transmission system will fly over the runway or another movement area and it will capture the image. The image is transmitted through the transmission system to the pilot and he will evaluate the image and determines whether the runway is contaminated/damaged (figure 1). He can do the necessary procedures eventually. The RPAS will be controlled by the pilot from the ground using the RC datalink.

The advantages of the airport operating areas inspection by the RPAS are greater flexibility and saved time. The control itself proceeds much faster than the conventional control. Thanks to this the control can be executed more frequently during the day. Among the benefits belong the data backup and subsequent evaluation e.g. small surface cracks. 


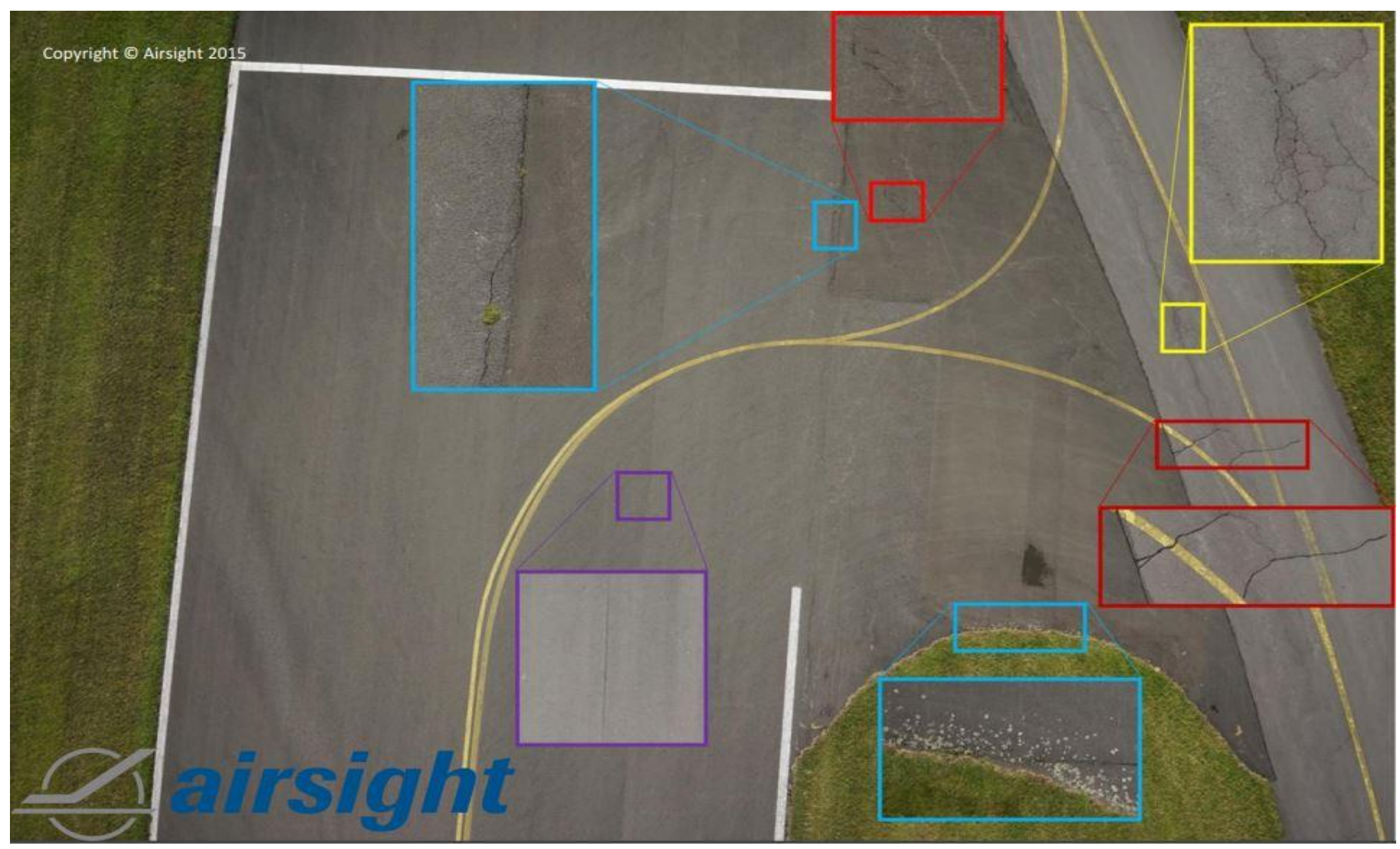

Figure 1: An example of the imaging the surface by the RPAS [2].

One of the possibilities how to inspect the surface is the use of the thermal imaging camera. For routine monitoring of the runway the conventional camera is better than the thermal imaging camera. The thermal imaging camera could detect objects radiating heat. For example small parts that have fallen out from the aircraft engine or small animals such as a rabbit can be overlooked by conventional camera with a lower resolution. The pilot cannot see these objects in the picture. The thermal imaging camera can discover these heat sources easily. The pilot can do the appropriate action to repel the animals or to pick up the part of the engine. However, if the warm objects which fell out from the aircraft on the runway are there for a long time, they will cool down and the detection by the thermal imaging camera will not be possible.

\section{TECHNICAL SOLUTIONS}

The RPAS control is realized by the RC datalink. The signal is received in $2.4 \mathrm{GHz}$ frequency band. The motion of the pilot's control sticks are received via electric signal to RPAS board. The signal is evaluated as a control motion to action elements. The autopilot on board of the aircraft is semiautomatic with automatic flight assistance.

\section{A. Semi-automatic}

It is the simplest type of the autopilot. The autopilot is not able to flight itself. It can be used together with the manual control. It assists the pilot with the control, for example: stabilization, maintaining the predefined altitude etc.

\section{B. Automatic}

The autopilot is able to fly according to a predefined program (for example: according to route). It reacts on the change of the conditions, for example: wind drift or barometric pressure change. The route can be modified during the flight.

The semi-automatic control is supposed to be the primary use due to legislative limitations. The possibility of using the automatic control flight is insured in the event that future legislation will allow flying through automatic control. Control will be performed manually by the pilot. The pilot had to maintain the visual reference with the aircraft during the flight or the pilot can use FPV technology. 


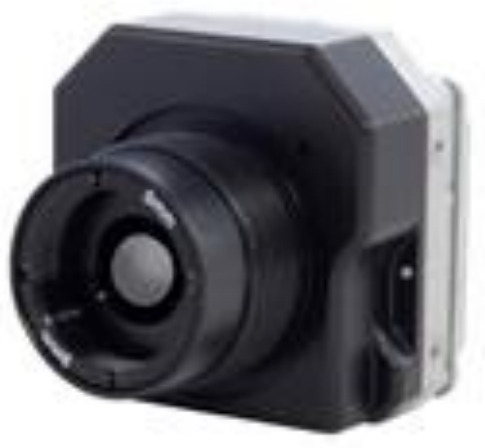

Figure 2: Thermal Imaging Camera Flir Tau2 [3].

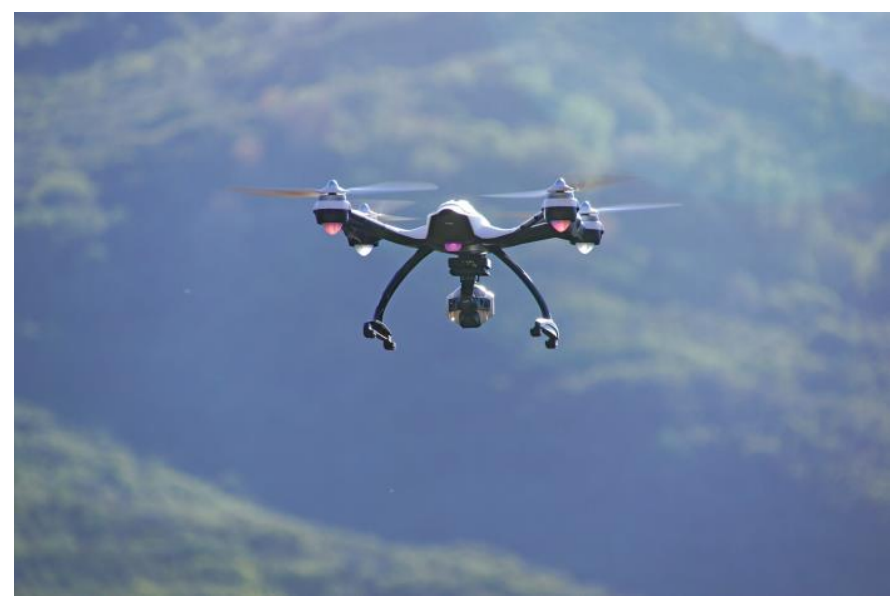

Figure 3: Simple RPAS for RWY check [5].

The RPAS's board is equipped with the device for image recording. The device screens the scenery under the airplane. The GoPro 4 Black is suggested as a screening device. Second on-board camera is a Fir Tau 2. It is a thermal imaging camera. The Flir Tau 2 takes image with the thermal resolution and sends the image to the ground station. The pilot receives the image about the objects with different temperature.

Table 1: Technical parameters for cameras: Flir Tau2 [3] and GoPro 4 Black [4].

\begin{tabular}{|c|c|c|}
\hline & Flir Tau 2 640 & GoPro 4 Black \\
\hline Lens & $7.5 \mathrm{~mm}$ & $5.4 \mathrm{~mm}$ \\
\hline Resolution & $640 \times 512$ & $3840 \times 2160$ \\
\hline Pixel Size & $17 \mu \mathrm{m}$ & $1,55 \mu \mathrm{m}$ \\
\hline View angle & $90^{\circ} \times 69^{\circ}$ & $90^{\circ}, 127^{\circ}, 170^{\circ}$ \\
\hline Analog Video & $\begin{array}{c}\text { Field-switchable } \\
\text { between }\end{array}$ & $\begin{array}{c}\text { analog-to-digital } \\
\text { converter }\end{array}$ \\
\hline $\begin{array}{c}\text { Minimum Focus } \\
\text { Distance }\end{array}$ & $2.5 \mathrm{~cm}$ & $* 12^{\prime \prime}$ \\
\hline $\begin{array}{c}\text { Weight (camera }+ \\
\text { lens) }\end{array}$ & $71 \mathrm{~g}$ & $88 \mathrm{~g}$ \\
\hline Dimensions & $1,75^{\prime \prime} \times 1,75^{\prime \prime} \times 1,18^{\prime \prime}$ & $3.9^{\prime \prime} \times 9.6^{\prime \prime} \times 3.9^{\prime \prime}$ \\
\hline
\end{tabular}

The broadcast of the analogue image FPV for the pilot is able to use these frequencies: $910 \mathrm{MHz}, 1.2 / 1.3 \mathrm{GHz}, 2.3 / 2.4$ $\mathrm{GHz}$ a $5.8 \mathrm{GHz}$. The frequency $5.8 \mathrm{GHz}$ is the most suitable for this purpose. The receiver and transmit antennas are very small and there is less interference from other electronic devices. The frequencies $2.3 / 2.4 \mathrm{GHz}$ are the same with frequency of datalink. There could be some interference in datalink. The $900 \mathrm{MHz}$ is long range signal but with noise in transmission.

\section{CONCLUSION}

The use of the RPAS for the inspection of the runways and other movement areas are a significant benefit. Using the RPAS will reduced scanning time and thereby increase the number of the inspection during the day. All concepts are not focused only to runway check vehicles. The RPAS can be used as an appropriate solution for the other processes. There are described functions of the RPAS for bird scanning. This extension cannot fully replace the current method of the inspection of the movement areas. It is only additional protection to the current inspection methods. This method allows more frequent monitoring with the possibility to eliminate operator error because it uses together with computer software. We are at the beginning of the process at the moment. There are a lot of legislative limitations for this purpose of use but it is only temporary. The whole process must be approved and introduced into the normal operation by relevant authorities.

\section{REFERENCES}

[1] ČESKÁ REPUBLIKA. Letecký předspis: L14 - Letiště. In: Zákon č 49/1997 $\quad S b . .2009 . \quad$ Dostupné také Z: <http://lis.rlp.cz/predpisy/predpisy/dokumenty/L/L-14/data/print/L-

14_cely.pdf>

[2] WATSON, Michael. UAVs and Airports. Aviation events international [online]. 2015 [cit. 2015-09-08]. Dostupné z: <http://www.aviationeventsinternational.com/pdfs/Mike-Watson.pdf>

[3] Tau 2 Uncooled Cores. Flir: OEM cores \& components [online]. 2015 [cit. 2015-09-12] Dostupné <http://www.flir.com/cores/display/?id=54717>

[4] CRISP, Simon. GoPro Hero4 vs. GoPro Hero3+. Gizmag [online]. 2014 [cit. 2015-09-12]. Dostupné z: <http://www.gizmag.com/gopro-hero4vs-gopro-hero3plus/34090/>

[5] AIN Online. European Helo Operators Mull Using Drones [online]. 2015. [cit. 2015-09-14]. Available from: < http://www.ainonline.com/aviation-news/business-aviation/2015-08 17/european-helo-operators-mull-using-drones>

[6] CAA New Zealand. RPAS, UAV, UAS, Drones and Model Aircraft. [online]. 2015. Available from: <http://www.caa.govt.nz/rpas/>

[7] MYFLYDREAM. Automatic Antenna Tracker: Manual. V 3.0. Available from: http://www.myflydream.com/download/AAT_en_3.0.pdf

[8] HIS Airport 360. ICAO debates detailed RPAS regulations. [online]. 2015. Available from: http://www.ihsairport360.com/article/6179/icao-debates-detailed-rpasregulations> 
